\title{
Characterization of crystals growth in a crystallizer-evaporator through Digital image processing using the sobel filter
}

\section{Juan Antonio Quintana Silva ${ }^{1}$, Fabián Cabrera Sánchez², Abraham Téllez Morales ${ }^{3}$, Anselmo Osorio Miron ${ }^{4}$}

\author{
${ }^{1,2}$ Instituto Tecnológico de Orizaba, División de Estudios de Posgrado e Investigación. México, Oriente 9 No. 818, Col. E. Zapata, C. \\ P. 94320, Orizaba, Veracruz. \\ ${ }^{3}$ Centro de Investigación y de Estudios Avanzados del Instituto Politécnico Nacional. México. \\ ${ }^{4}$ Facultad de Ciencias Químicas, Universidad Veracruzana. México, Universidad Veracruzana, Facultad de Ciencias Químicas, México. \\ Prolongación Oriente 6 No. 1009, Col. Rafael Alvarado, C. P. Orizaba, Veracruz, México. Tel/Fax (+52) 2727240120
}

Email: jaquintanas@hotmail.com, levicabrera@hotmail.com,tellez_777@hotmail.com, anselmo_osorio@yahoo.com

Received: January $09^{\text {th }}, 2018$.

Accepted: February $01^{\text {th }}, 2018$.

Published: March 30 ${ }^{\text {th }}, 2018$.

Copyright (C2016 by authors and Institute of Technology Galileo of Amazon (ITEGAM).

This work is licensed under the Creative Commons Attribution International

License (CC BY 4.0).

http://creativecommons.org/licenses/by/4.0/ (c) (1) (2) Opea Actes:

\begin{abstract}
The sugar is consumed world widely, because it is one of the main sources of calories in the diets of every country. For its obtaining, a long process is required, since the cane seed germinates until the sugar is marketed nationally or internationally. Inside the obtaining process of the sugar it is found the stage of crystallization. The work presented in this article, proposes a digital image processing technique based on the Sobel filter. The obtained results let to characterize the sugarcane crystal growth in a simple effect evaporator-crystallizer in order to define when the crystallization process must be finished.
\end{abstract}

Keywords: Sugar, Characterization, Growth, Crystallization, Segmentation, Image.

\section{Caracterización del crecimiento de cristales en un evaporador- cristalizador mediante procesamiento digital de imagen utilizando el filtro sobel}

\section{RESUMEN}

El azúcar se consume en todo el mundo, ya que es una de las principales fuentes de calorías en las dietas de todos los países. Para su obtención se requiere de un largo proceso, desde que la semilla de caña germina hasta que el azúcar se comercializa nacional o internacionalmente. Dentro del proceso de obtención del azúcar se encuentra la etapa de cristalización. El presente trabajo propone una técnica de procesamiento digital de imagen basada en el filtro Sobel. Los resultados obtenidos permiten caracterizar el crecimiento de cristales de caña de azúcar en un evaporador-cristalizador de simple efecto para definir el momento en que se debe finalizar el proceso de cristalización.

Palabras Clave: Azúcar, Caracterización, Crecimiento, Cristalización, Segmentación, Imagen.

\section{INTRODUCCIÓN}

La agroindustria azucarera es una actividad relevante para la economía nacional según los recursos que absorbe su proceso laboral y comercialización, por el valor de su producción y por el tipo de consumo que experimenta su producto final. La caña de azúcar ha sido sin lugar a dudas uno de los productos de mayor importancia para el desarrollo comercial del continente americano y europeo. Contribuye con poco mas de $0.5 \%$ en el producto nacional bruto; con el $2.32 \%$ en el producto del sector manufacturero, y con el $12.5 \%$ en el producto del sector alimentario.

La agroindustria cañera genera alrededor de 300 mil empleos directos, distribuidos en las figuras de productores primarios directos, jornaleros, obreros fabriles y empleados de confianza. La mayor proporción de los empleos directos se ubican en el ámbito rural, esto es aproximadamente un $74 \%$. Se estima que más de 3 millones de personas dependen directa o indirectamente de la agroindustria cañera.

A nivel nacional, la caña de azúcar al lado del café, naranja, plátano, alfalfa, coco y maguey, figura como uno de los 
principales cultivos de producción continua del país. Los campos cañeros se encuentran distribuidos en 15 estados de la República: Campeche, Chiapas, Colima, Jalisco, Michoacán, Morelos, Nayarit, Oaxaca, Puebla, Quintana Roo, San Luis Potosí, Sinaloa, Tabasco, Tamaulipas y Veracruz. Según estadísticas de la FAO y de la UNESCO, México es uno de los 10 países con mayor superficie cosechada y de mayor producción de caña de azúcar a nivel mundial [1].

El azúcar se consume en todo el mundo, ya que es una de las principales fuentes de calorías en las dietas de todos los países. En México tiene una considerable magnitud de mercado, su consumo es generalizado en el ámbito doméstico y tiene una importante demanda en el sector industrial, ejemplos de esto son la industria refresquera, galletera, alcoholera, dulcera y la de alimentos balanceados para alimentación animal. El azúcar es un producto de consumo básico para la población mexicana, junto con maíz, frijol, trigo y café [2].

Para su obtención se requiere de un largo proceso, desde que la semilla de caña germina hasta que el azúcar se comercializa, nacional o internacionalmente. Las etapas que más destacan son: Molienda o trapichado de la caña, purificación de los jugos, filtración, evaporación, cristalización, centrifugación, secado y envasado.

El azúcar, en su etapa final, es un producto natural, sólido y que se manifiesta en forma de cristales [3]. La obtención de los mismos, se lleva a cabo mediante un proceso complejo. Esta complejidad surge debido a diversas circunstancias, entre las cuales destacan, la temperatura, el grado de saturación en la solución, agitación de la solución contenida en el cristalizador, impurezas en la solución, etc. Se puede empezar a notar la presencia de cristales de azúcar cuando el jugo de caña se concentra y llega a un estado de sobresaturación.

La cristalización es un proceso por medio del cual se logra llevar a una sustancia a la forma de solido cristalino partiendo de la misma sustancia fundida o de su disolución en un disolvente apropiado. Aunque pueden citarse algunos casos, también puede ser la cristalización de una sustancia partiendo de una fase vapor, sin pasar por el estado liquido. Es también importante como medio para purificar muchas sustancias y como método de fraccionamiento de mezclas de sustancias disueltas [4].

El interés químico-técnico de esta operación es que los sólidos cristalinos se manejan y transportan con más facilidad que las disoluciones y ocupan menos espacio, por lo cual esta forma es la preferida para la presentación de muchos productos. Entre las aplicaciones industriales de la cristalización, alcanzan gran importancia la obtención y purificación de sales minerales diversas, la de productos químicos, la de productos químicofarmacéuticos, la de productos intermedios para la industria químico-orgánica, el desparafinado de los aceites lubricantes para la obtención de estearinas para bujías, estearatos metálicos, etc.

En la industria metalúrgica, la forma de conducir la cristalización de las masas metálicas fundidas es decisiva para la calidad de los productos terminados, y en el caso en la industria de la alimentación, para obtener azúcar, mantequilla y margarinas, entre otros productos.

Los objetivos principales del proceso de cristalización se basan en tres elementos: el rendimiento, pureza elevada y distribución del tamaño de los cristales [5].

Estas características deben estar presentes durante todo el proceso donde se lleva a cabo la cristalización, sin embargo en la industria azucarera, el proceso es vigilado por una persona que es la responsable de decidir si el proceso de cristalización ha finalizado o si se debe continuar hasta obtener las condiciones necesarias para proseguir con el proceso de secado y envasado.
Esto da pauta para ofrecer al encargado del proceso de cristalización, una herramienta en la toma de decisiones, para reducir los errores basados en la experiencia subjetiva del personal y maximizar la calidad del producto. La herramienta a proponer se basa en el procesamiento digital de imágenes.

En este trabajo se propone la realización de la medición del tamaño de los cristales de azúcar de caña a través de esta técnica de procesamiento de imágenes, cuyo rango de aplicación abarca procesos en los cuales las entradas y las salidas son imágenes, en adición, abarca procesos que extraen atributos de las imágenes incluyendo el reconocimiento de objetos individuales [6].

\section{METODOLOGÍA}

Las corridas experimentales se desarrollaron en un evaporador-cristalizador de simple efecto. Este equipo es calentado con vapor que circula en el interior de la chaqueta del cristalizador. De manera simultánea, un agitador mantiene uniforme a la solución dentro del mismo, Figura 1.

Las muestras obtenidas en el evaporador-cristalizador se observaron en un microscopio DC5-163, de National Instruments, que cuenta con un protocolo de comunicación mediante el puerto USB.

Este instrumento se conecta al ordenador para poder observar y adquirir las imágenes en la Figura 2.

El instrumento utilizado para medir la concentración de las distintas muestras, fue un refractómetro analógico manual, marca Atago, modelo 486284 en la Figura 3 [7].

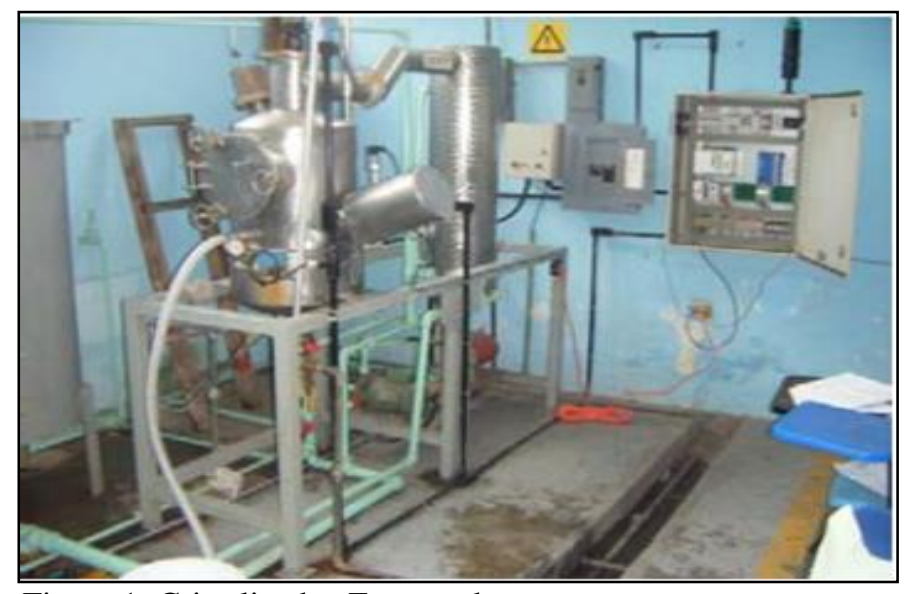

Figura 1: Cristalizador-Evaporador.

Fuente: Los autores, (2018).

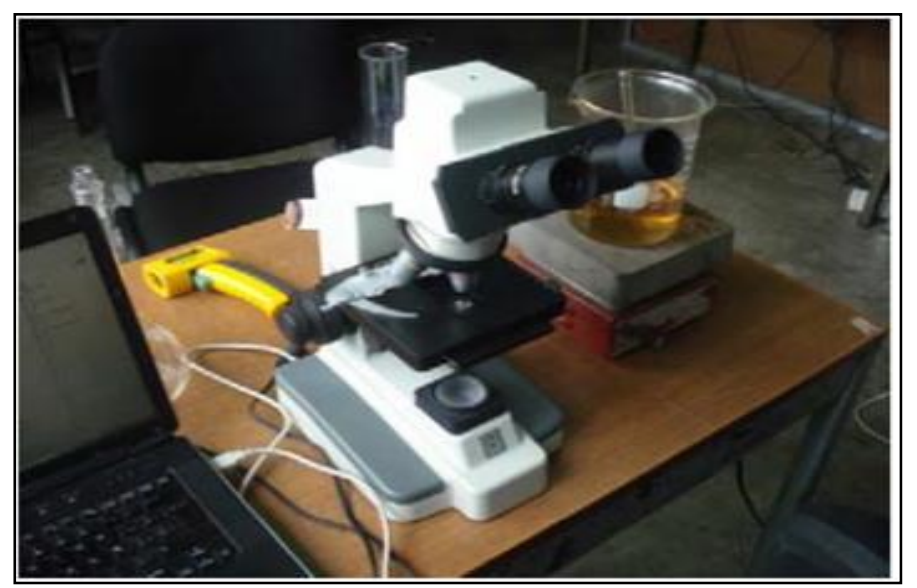

Figura 2: Microscopio National Instruments, DC5-163.

Fuente: Los autores, (2018). 


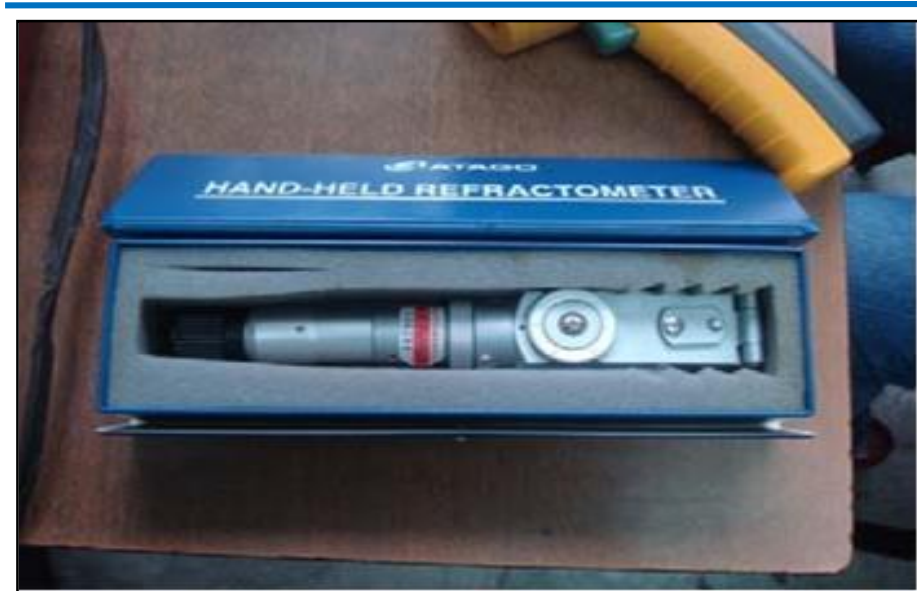

Figura 3: Refractómetro analógico.

Fuente: Los autores, (2018).

Una vez que la muestra de la solución se obtiene del cristalizador se observa a través del microscopio, para su posterior procesamiento digital con ayuda de un algoritmo computacional. La forma en la que se logra medir el crecimiento de los cristales formados en la solución será mediante una técnica de segmentación basada en el filtro Sobel.

La manera en la cual se realiza el procesamiento de la imagen se plantea de la manera siguiente: se obtiene la imagen mediante el microscopio, se procesa la imagen y se aplica el algoritmo de segmentación, se mide el tamaño de los cristales y se compara el valor actual con el valor deseado para dar opción a dos posibles respuestas: continuar con el proceso de cristalización o detener el proceso dentro del cristalizador. En la Figura 4 se muestra un diagrama de flujo acerca del proceso elaborado en el tratamiento de la imagen.

\begin{tabular}{|cccc|}
\hline $\begin{array}{c}\text { Inicia proceso } \\
\text { de } \\
\text { cristalización }\end{array}$ & $\begin{array}{c}\text { Obtener } \\
\text { imagen de la } \\
\text { solución }\end{array}$ & $\begin{array}{l}\text { Proceso de } \\
\text { imagen } \\
\text { aplicación } \\
\text { algoritmo }\end{array}$ & $\begin{array}{r}\text { la } \\
\text { de }\end{array}$ \\
No & Segmentación \\
de la imagen \\
envasado
\end{tabular}

Figura 4: Diagrama de flujo del proceso de cristalización y procesamiento de la imagen.

Fuente: Los autores, (2018).

El método mostrado ofrece una alternativa para poder determinar el momento en que la cristalización dentro del equipo piloto se ha realizado. Esto tendrá como respuesta un producto de mejor calidad en el mercado, reducción de los tiempos y costos, y el uso de tecnologías actuales implementadas en la generación de productos de un valor agregado alto.

\section{RESULTADOS}

Las imágenes que se presentan a continuación; manifiestan características que hacen más difícil el proceso de segmentación. Para corregir este problema se debe hacer un pre-procesamiento a la imagen para poder tratarla.
El proceso de cristalización, es un proceso complejo. Se tienen que conocer los eventos que conforman este suceso, así como las condiciones que tienen que estar presentes para poder lograr el crecimiento de cristales y poder observarlos a través de una imagen para su posterior tratamiento digital. Las imágenes presentadas muestran diferentes crecimientos de cristales, a distintas concentraciones en la solución. En la Figura 5, se muestra una imagen a una concentración de $69^{\circ}$ Brix. En la Fig. 6 , se tiene una imagen a $73^{\circ}$ Brix mientras que una concentración de $80^{\circ}$ Brix se observa en la Figura 7 . Para $83^{\circ}$ Brix, la imagen se puede ver en la Figura 8.

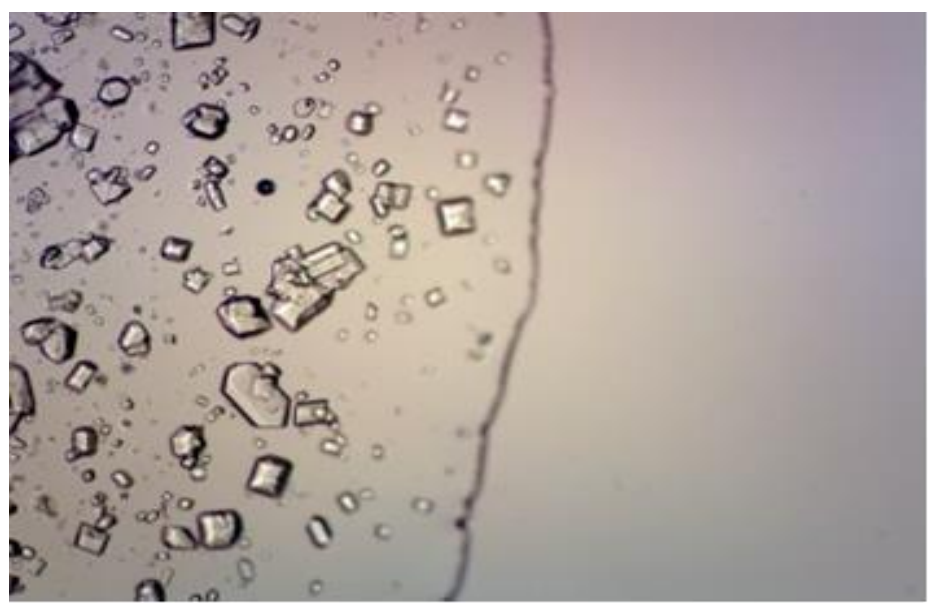

Figura 5: Solución a $69^{\circ}$ Brix.

Fuente: Los autores, (2018).

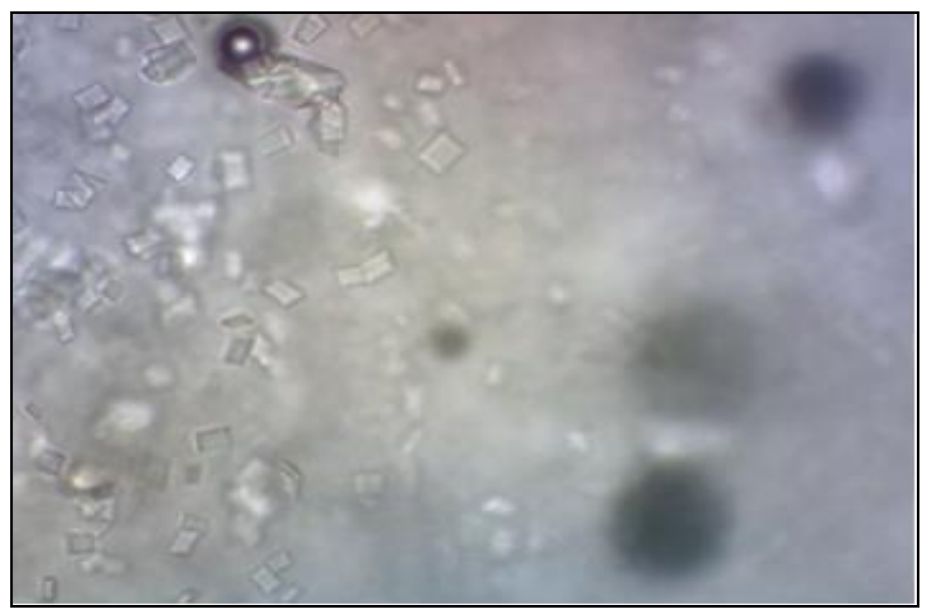

Figura 6: Solución a $73^{\circ}$ Brix.

Fuente: Los autores, (2018).

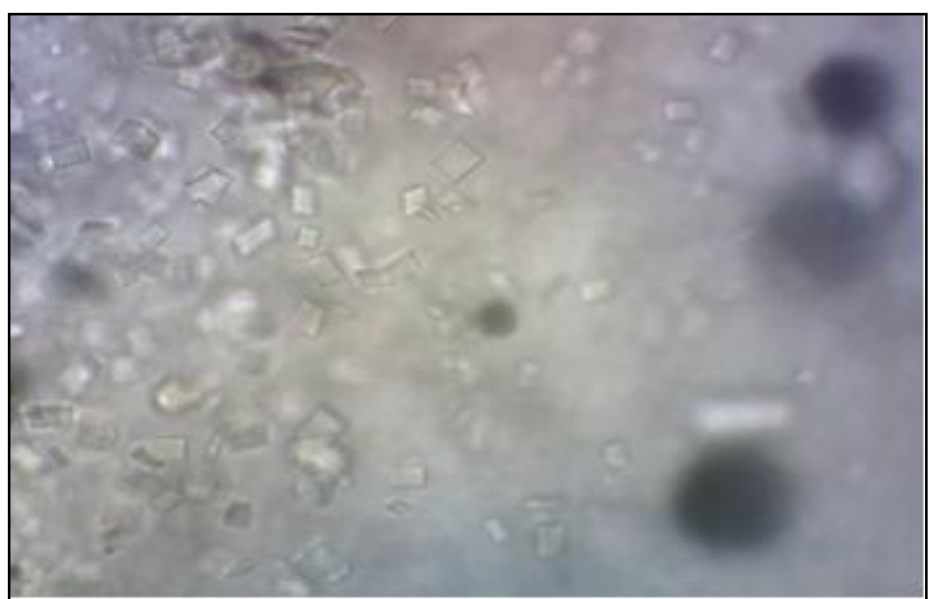

Figura 7: Solución a $80^{\circ}$ Brix.

Fuente: Los autores, (2018). 


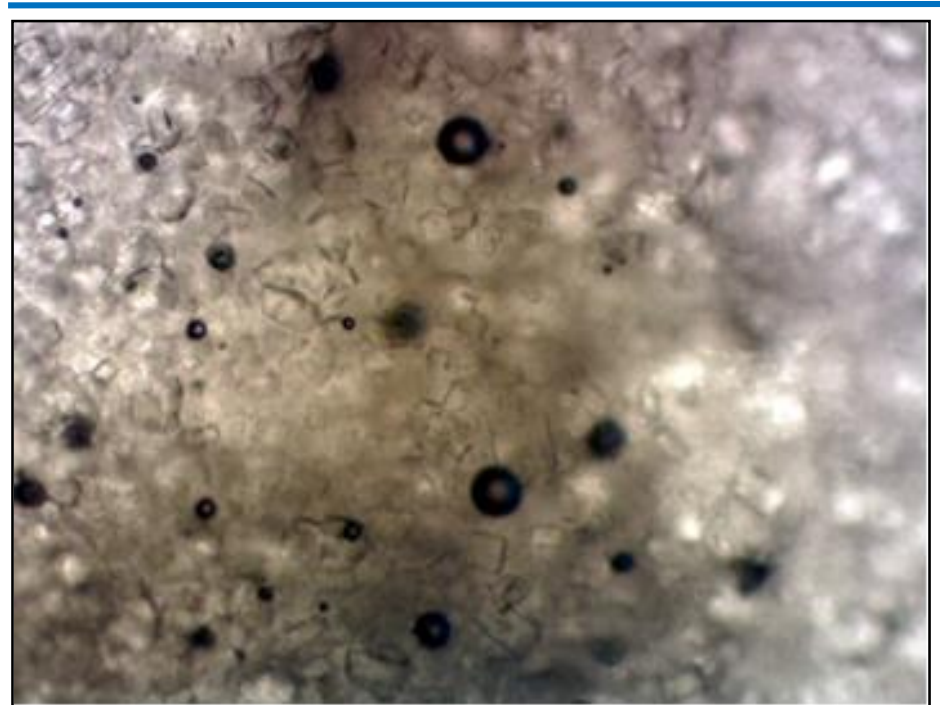

Figura 8: Solución a $80^{\circ}$ Brix.

Fuente: Los autores, (2018).

Las imágenes del crecimiento de cristales que se muestran en las figuras 5-8, proporcionan una idea de lo que se desea obtener para detener el proceso de cristalización. Sin embargo es necesario aclarar que lo que se busca, son cristales con un tamaño y forma específicos, que faciliten el procesamiento de la imagen. Por esta razón, la imagen de la Figura 5 es la que se proceso para obtener los datos requeridos y dar fin a la cristalización en el evaporador. Imágenes obtenidas con saturación inferior a $70^{\circ}$ Brix no presentan crecimiento de cristales, o manifiestan solo algunos cristales. Imágenes superiores a $85^{\circ}$ grados Brix, presentan una solución sobresaturada y repleta de cristales que impide que se observen claramente, debido a que forman una masa compacta, semejante a un caramelo. El rango idóneo, después de muchas pruebas; se pudo observar entre $77^{\circ}$ y $82^{\circ}$ Brix.

El procesamiento realizado a la imagen consiste en leer la imagen, convertirla a escala de grises, corregir los efectos de iluminación, incrementar los contrastes, para posteriormente aplicar el algoritmo de segmentación [8]. El programa usado para desarrollar el algoritmo es MATLAB versión 7.0. Se puede definir a la segmentación de una imagen, como un proceso de detección de objetos.

Los cambios en el contraste de una imagen pueden ser detectados con operadores que calculan el gradiente de una imagen. Este gradiente puede ser calculado y un umbral puede ser aplicado para crear un mapa binario que contenga los cristales.

Se denomina mapa binario a una imagen en donde se muestra un fondo negro con los contornos de los cristales en color blanco, Figura 9. Esta imagen se interpreta en MATLAB como datos con valores de 0's y 1's. [9].

A esta imagen segmentada se le aplica un proceso de dilatación debido a la aparición de brechas que están dentro del cristal mostrado. Figura 10.

Una vez dilatada la imagen se procede a rellenar la imagen para que muestre la figura de un cristal. Figura11.

Se eliminan los elementos que se encuentren al borde de la imagen, mediante un comando que permite realizar esta acción. Figura 12. Enseguida se aplica un procedimiento de alisado a la imagen, a este proceso se le conoce como Smooth. Figura 13.

Finalmente se obtiene el tamaño promedio de los cristales visualizados en la imagen. El valor que se obtiene es de 211. 41 elementos de imagen.

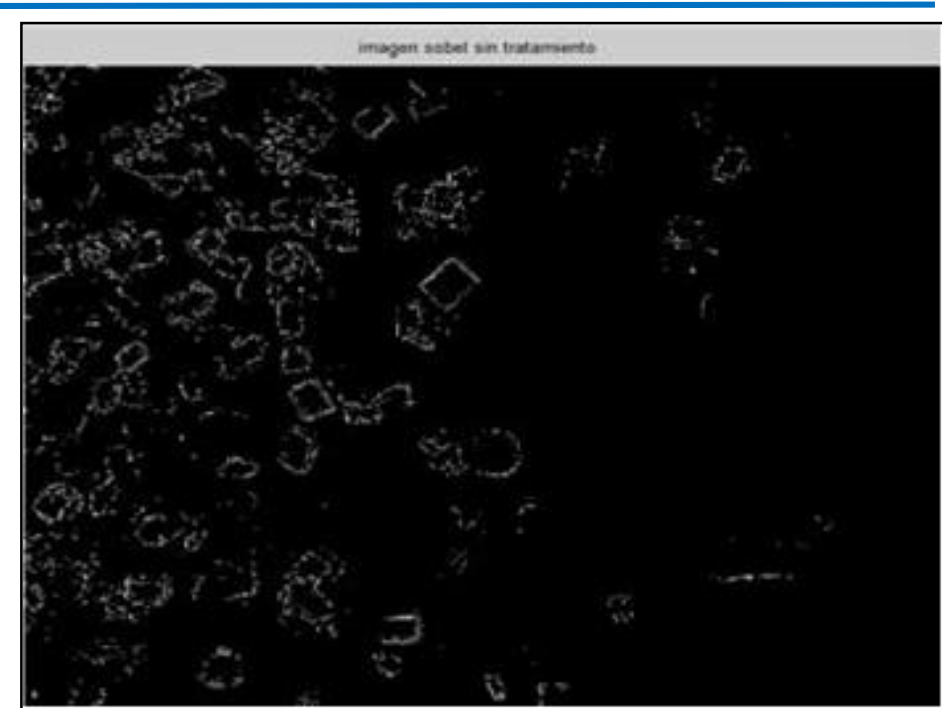

Figura 9: Imagen Segmentada.

Fuente: Los autores, (2018).

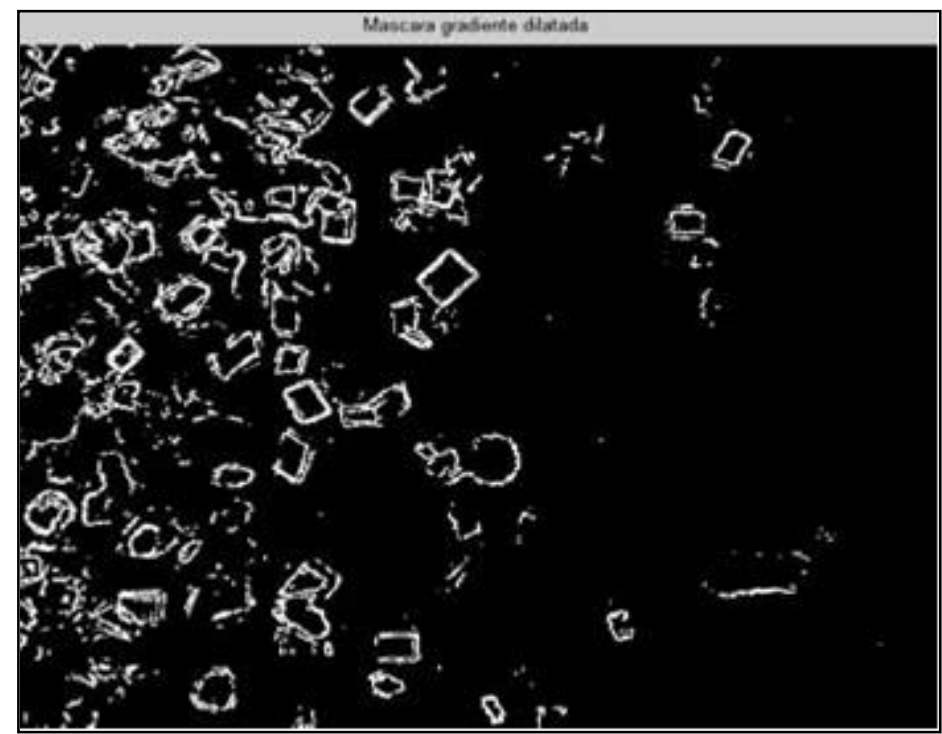

Figura 10: Imagen Dilatada.

Fuente: Los autores, (2018).

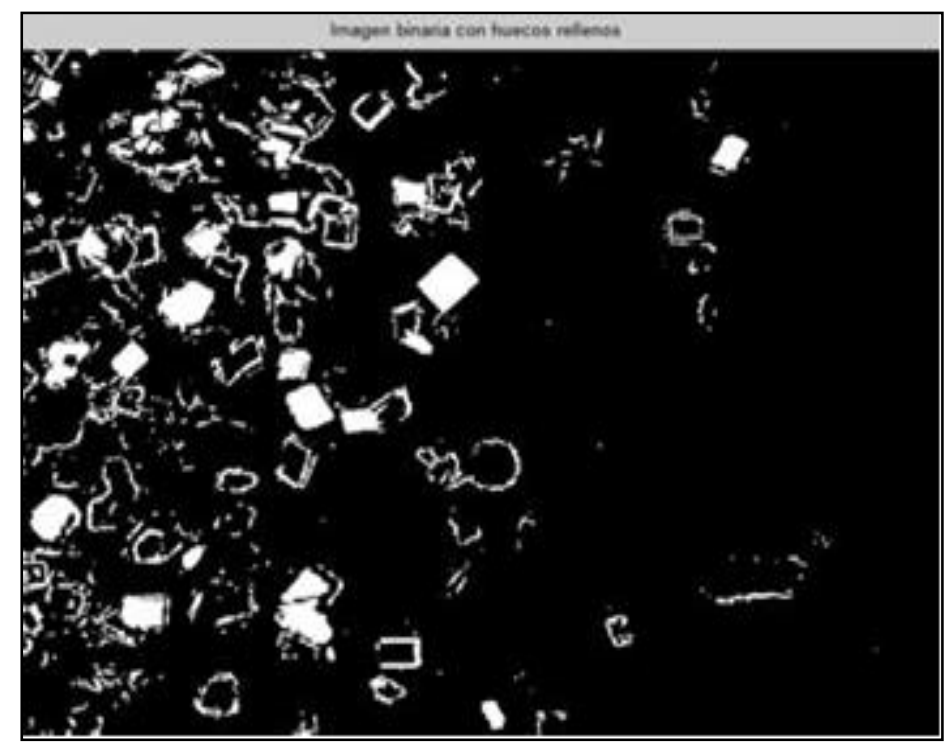

Figura 11: Imagen Rellenada.

Fuente: Los autores, (2018). 


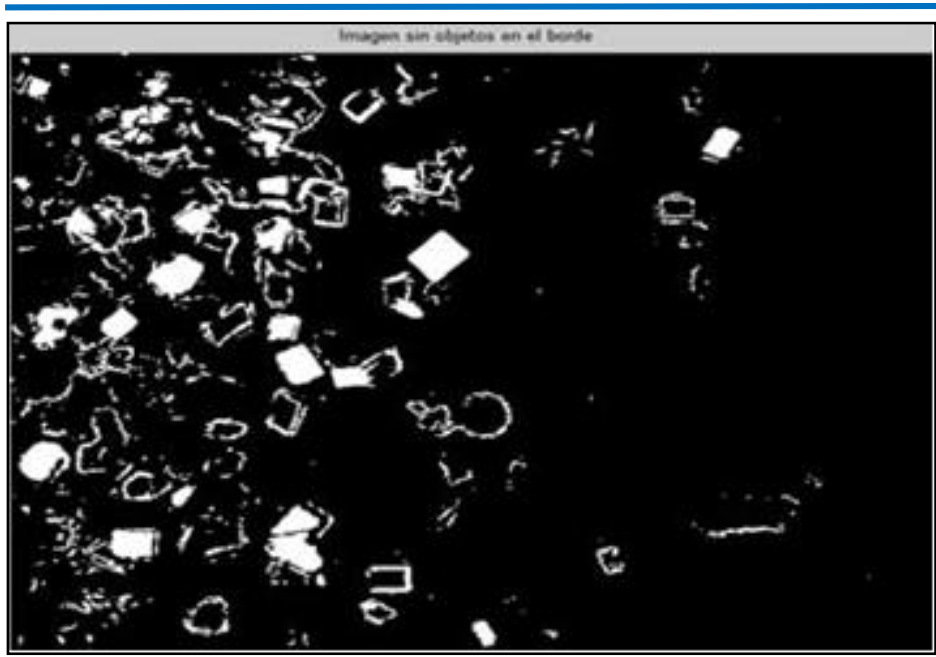

Figura 12: Imagen Sin Objetos en el borde.

Fuente: Los autores, (2018).

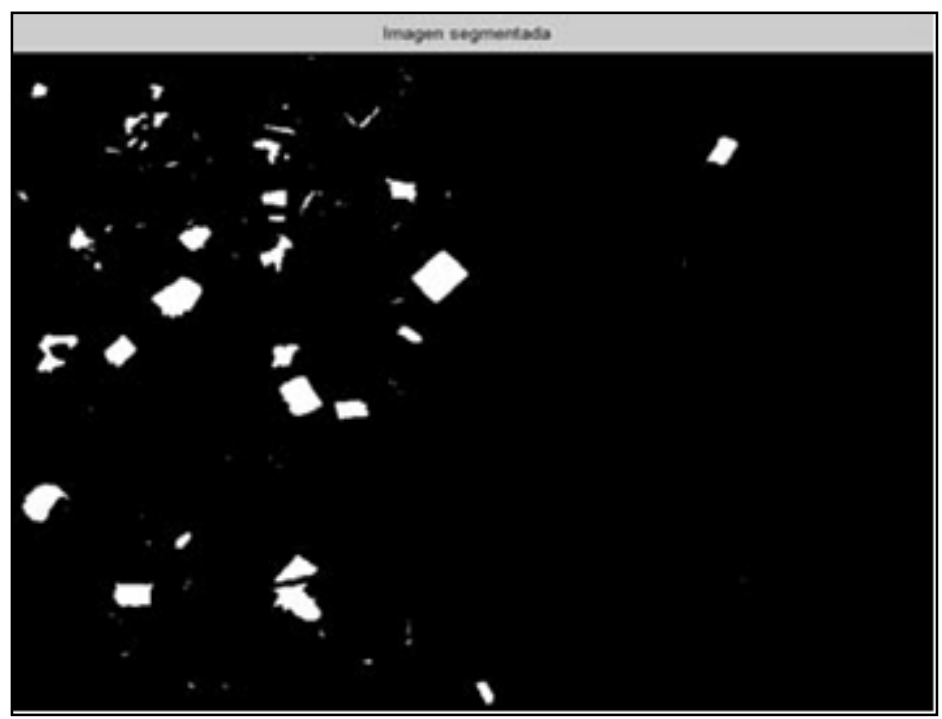

Figura 13: Imagen Alisada.

Fuente: Los autores, (2018).

El procesamiento de las imágenes de cristales de azúcar fue realizado usando un filtro tipo pasa altas, llamado filtro Sobel. Este tipo de filtro permite detectar y dar realce a los bordes. También permite detectarlos horizontal y verticalmente o de manera independiente. Su característica más importante es que es mucho menos sensible al ruido comparado con otros filtros [10].

El detector de bordes Sobel usa la máscara de la Figura 14, para aproximar digitalmente la primera derivada Gx y Gy. En otras palabras, el gradiente en el punto central en una vecindad, es computarizado como se muestra a continuación por el detector Sobel.

$$
\begin{aligned}
& g=\left[G_{x}^{2}+G_{y}^{2}\right]^{1 / 2} \\
& g=\left\{\left[\left(z_{7}+2 z_{8}+z_{9}\right)-\left(z_{1}+2 z_{2}+z_{3}\right)\right]^{2} \ldots\right. \\
& \left.\left.\ldots+\left(z_{3}+2 z_{6}+z_{9}\right)-\left(z_{1}+2 z_{4}+z_{7}\right)\right]^{2}\right\}^{1 / 2}
\end{aligned}
$$

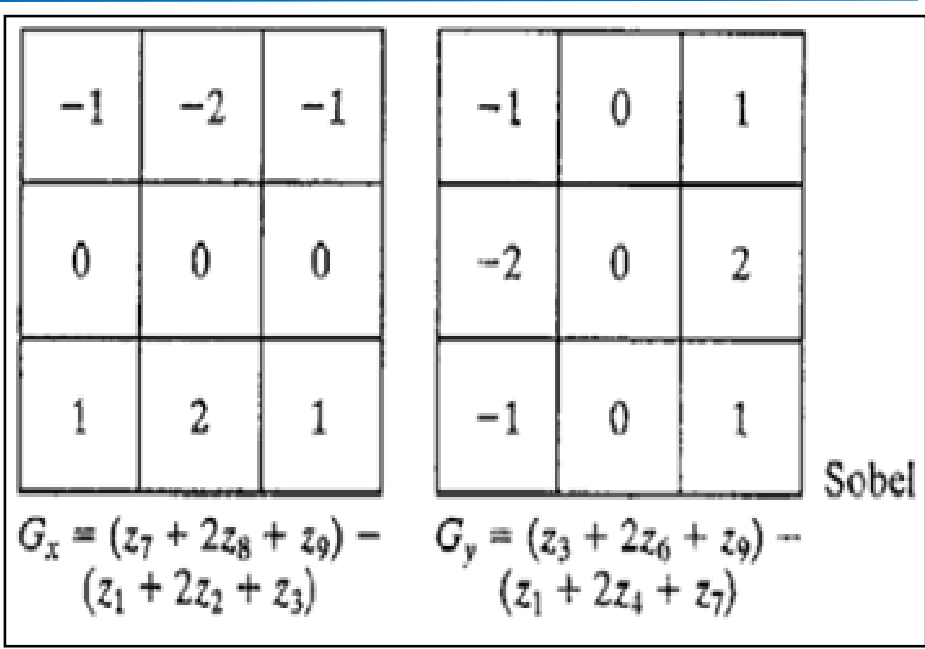

Figura 14: Mascara detectora de bordes y su derivada de primer orden que implementa.

Fuente: Los autores, (2018).

La sintaxis general de llamada para el filtro sobel es:

$[\mathrm{g}, \mathrm{t}]=$ edge(f,'sobel', T, dir)

donde ' $\mathrm{g}$ ' es una imagen lógica conteniendo 1's en las posiciones donde los bordes fueron detectados y 0's en otras partes. El parámetro ' $t$ ' en la salida es opcional, es el valor de umbral usado en el borde, ' $\mathrm{f}$ ' es la imagen de entrada, ' $\mathrm{T}$ ' es un umbral especifico y 'dir' especifica la dirección principal de los bordes detectados: 'Horizontales', 'Verticales' o 'ambos' (Por default) [6].

\section{CONCLUSIONES}

Los resultados permitirán detectar el momento en que se inicia la cristalización, darle seguimiento y determinar el punto final del proceso; así como contribuir como herramienta alterna a la toma de decisiones por parte de los operadores del equipo de cristalización.

La técnica usada para detectar objetos en una imagen se basa en el detector de bordes Sobel, cuya característica principal es que el ruido lo afecta en menor medida, lo que reduce el uso de técnicas de pre-procesamiento, generando una imagen con características de calidad.

La detección de los cristales de azúcar, a través del procesamiento de imágenes del proceso, permitirán direccionar los trabajos futuros, hacia el monitoreo en línea y/o al diseño de algoritmos de control en lazo abierto o en lazo cerrado, para mantener las características principales del producto en los niveles deseados.

\section{REFERENCIAS}

[1] Figueroa Sandoval B., González Cossío F., Jaimes Escobedo A. (Noviembre 2003). Caracterización de la agroindustria caña de azúcar e identificación de las demandas tecnológicas. [En línea]. Disponible en: www.snitt.org.mx/pdfs/demanda/canadeazucar. pdf

[2] Alvarado Arenas Y., "Proceso azucarero", Tesis de profesional técnico químico en procesos de producción, Depto., de química, Colegio Nacional de educación profesional Técnica, plantel 252, Orizaba, México, 1997. Sociedad Agrícola e Industrial San Carlos S.A. (Noviembre 2005). Proceso de 
elaboración del azúcar. [En línea] Disponible en: www.sancarlos.com.ec/pdf/proceso_azucar.pdf.

[3] Vian A., Ocón J. Elementos de ingeniería Química (Operaciones Básicas), 5ta edición, Aguilar S.A. de ediciones, 1976, pp., 695-698.

[4] McCabe W., Smith J., Harriott P. Operaciones Unitarias en Ingeniería Química, 4ta. Edición, McGraw-Hill, 2003, pp. 925931.

[5] Gonzales R. Woods R. Eddins S. Digital Image Processing Using Matlab. 1ra. Edición, Prentice Hall, 2005, pp. 378-425.

[6] PCE Ibérica S.L. Refractómetro de mano, Instrucciones de uso. (Septiembre 2006). [En línea]. Disponible en: www.pceiberica.es/manuales/manual-refractometromanual. pdf

[7] Detección de bordes en una imagen (Noviembre 2006). [En línea].

Disponible

en:

www4.ujaen.es/ satorres/practicas/practica3_vc. pdf

[8] The MathWorks, Inc. Manual de referencia de matlab. Versión 2007. García Bernal S. (Enero 2008) Manual Azul Nodos

[En línea]. Disponible en: www.zonanim.com/azul/azul-nodosr2.01. pdf 